\title{
Expression and chromosomal localization of KIAA0369, a putative kinase structurally related to Doublecortin
}

\begin{abstract}
Neuropathy in vertebrates can be a consequence of failure of genes involved in the nervous system to be expressed at the correct times and levels during embryonic life. Recently, a brain specific gene, Doublecortin, was cloned and was shown to have mutations in X-linked lissencephaly and double cortex syndrome. KIAA0369 is a putative kinase that is structurally related to Doublecortin. We compared the expression of KIAA0369 with that of Doublecortin, both of which were expressed specifically or predominantly in fetal brain among 20 different tissues examined. The deduced products of both genes contain a unique domain (the Doublecortin [DC] domain), but KIAA0369 also contains a calmodulin-dependent kinase (CaM kinase)-like domain following the DC domain. We found at least four splicing variants of KIAA0369: KIAA0369-AS (type A, short version), KIAA0369-AL (type A, long version), KIAA0369-BS (type B, short version), and KIAA0369-BL (type B, long version). KIAA0369-B, which lacked the DC domain and maintained the kinase domain, was expressed in adult as well as fetal brain, but the variants that included the DC domain, KIAA0369-A, were expressed predominantly in fetal brain. These results suggest that the DC domain plays an important role in the development of the nervous system. In the adult brain, KIAA0369 was expressed in all 15 different regions examined, more intensely in cerebral cortex, occipital pole, frontal lobe, amygdala, and hippocampus, and less intensely in corpus callosum and thalamus. The murine homologs of Doublecortin and KIAA0369 were not detectable in 7-day mouse embryos, but both genes were expressed extensively in 11-day embryos. Human KIAA0369 was mapped by fluorescence in situ hybridiza-
\end{abstract}

Y. Omori · M. Suzuki · K. Ozaki · Y. Harada · E-I. Takahashi

T. Fujiwara $(\bowtie)$

Otsuka GEN Research Institute, Otsuka Pharmaceutical Co., Ltd., 463-10 Kagasuno, Kawauchi-cho, Tokushima 771-0192, Japan

Tel. +81-886-65-2888; Fax +81-886-37-1035

e-mail: tfuji@gen.otsuka.genome.ad.jp

Y. Nakamura

Laboratory of Molecular Medicine, Institute of Medical Science, The

University of Tokyo, Tokyo, Japan tion (FISH) to chromosome 13q13-q14.1. The presence of genes related to neuropathy has been reported in this locus.

Key words Doublecortin · KIAA0369 - CaM kinase · Developmental nervous system · Neuropathy · Lissencephaly · Double cortex

\section{Introduction}

During the development of the vertebrate nervous system, many genes must be accurately controlled as to the time and level of expression. The dysfunction of such genes is implicated in various neuropathies in mammals. Murine reelin, a secretory protein, participates in the migration of neurons in the developing nervous system of the mouse; animals with defects in this gene exhibit tremors, dystonia, and ataxia (D'Arcangelo et al. 1995). In humans, mutations of L1, a cell-adhesion molecule involved in neuronal migration and differentiation, cause X-linked hydrocephalus, spastic paraplegia type I, and mental retardation, aphasia, shuffling gait and adducted thumbs (MASA) syndrome (Jouet et al. 1994); and Sox-3, a DNA- binding protein expressed predominantly in the developing nervous system, is regarded as a candidate gene for X-linked mental retardation (Mumm et al. 1997; Wolff et al. 1997).

Recently, a brain specific gene, Doublecortin, was cloned and was shown to have mutations in X-linked lissencephaly and double cortex syndrome (des Portes et al. 1998; Gleeson et al. 1998). These disorders were mapped to $\mathrm{Xq} 22.3-\mathrm{q} 23$, and were associated with the arrest of migrating cerebral cortical neurons. Doublecortin seemed to be involved in neural migration. KIAA0369, originally reported as one of 100 sequences isolated from a human-brain cDNA library (Nagase et al. 1997), has a highly conserved domain with Doublecortin in the N-terminus, and also contains a $\mathrm{Ca}^{2+} /$ calmodulin-dependent kinase (CaM kinase)like domain following it. CaM kinase participates in diverse calcium signaling pathways and mediates the regulation of many cellular functions, such as muscle contraction, neurotransmitter release, and cell proliferation (Hanson and 
Schulman 1992; Nairn and Picciotto 1994). Some CaM kinases are abundant in brain; in particular, CaM kinase II is of interest in relation to long-term potentiation (LTP) in the hippocampus (Soderling 1993; Lisman 1994).

In this study we investigated the expression pattern and chromosomal localization of KIAA0369.

\section{Materials and methods}

\section{Cloning and DNA sequencing}

As part of the human genome project, we have determined about 30,000 expressed sequence tags (ESTs) of cDNA clones randomly selected from human fetal brain, adult aorta, and placenta cDNA libraries, and deposited them in the public database. These experiments were performed in the manner described elsewhere (Watanabe et al. 1996 a,b). In the course of these studies we isolated two genes, Doublecortin and KIAA0369, from fetal brain.

For the cloning of Doublecortin, several 5'RACE (5' rapid amplification of cDNA ends) experiments were carried out, using Marathon-Ready Human Fetal Brain cDNA (Clontech, Palo Alto, CA) according to the protocol of the manufacturer. For the last 5'RACE, the polymerase chain reaction (PCR) was performed at an annealing temperature of $62^{\circ} \mathrm{C}$, using as primers DC-P3 (5'CAGATGTTTTTACGTTGACAGACCAG-3') and DC-P2 (5'-CCGATTTTCCTGGATCCATCAATG-3'). For the cloning of KIAA0369, the PCR was performed at an annealing temperature of $62^{\circ} \mathrm{C}$, using the following primers: for KIAA0369-A, KI-P1 (5'-CGGACCGGTCCTACTTGAAGTCCAT-3') and KI-P8 (5'-TCTGCCATTCAAGCATTGAGCGCTAG-3'); for KIAA0369-B, KI-P7 (5'-GGGCAGGTTTAGCCATCCTTAAACTC$\left.3^{\prime}\right)$ and KI-P8. Sequencing was performed with an ABI 377 sequencer (Applied Biosystems, Foster City, CA).

\section{Northern-blot analysis}

Northern-blot analyses were performed with the following Multiple Tissue Northern Blots (Clontech): Human, Human II, Human Fetal II, Human Brain II, Human Brain III, and Mouse Embryo. The probes were produced by PCR using the primers DC-P2 and DC-P5 (5'-CAGCGCCCACTGTAGCTTCTAC-3') for Doublecortin; KI-P1 and KI-P2 (5'-ATGGCATCGGTGATATCGGTGAGGAC-3') for KIAA0369-A; and KI-P3 (5'-CATCCCTGGGTTAATGATGATGGCCT-3') and KI-P4 (5'-GTAGTCTTCCGATTCCGAGTTGAGTTC-3') for KIAA0369-A+B. The PCR products were purified and labeled with $\left[{ }^{32} \mathrm{P}\right]$-deoxycytidine $5^{\prime}$ triphosphate (dCTP) (BcaBEST Labeling Kit, Takara, Kyoto, Japan). Blots were prehybridized for $3 \mathrm{~h}$ and then hybridized for $18 \mathrm{~h}$ at $42^{\circ} \mathrm{C}$ in a mixture of $50 \%$ formamide, $5 \times$ standard sodium citrate (SSC), $10 \times$ Denhardt's solution, and $2 \%$ sodium dodecylsulfate (SDS) containing
$100 \mu \mathrm{g} / \mathrm{ml}$ denatured salmon sperm DNA. Hybridized blots were washed with $2 \times \mathrm{SSC}, 0.5 \% \mathrm{SDS}$ at room temperature for $40 \mathrm{~min}$, and then with $0.2 \times \mathrm{SSC}, 0.1 \% \mathrm{SDS}$ at $42^{\circ} \mathrm{C}$ for $40 \mathrm{~min}$.

BAC cloning and chromosomal localization by direct R-banding fluorescence in situ hybridization (FISH)

BAC clones were isolated from the human BAC library (Research Genetics, Huntsville, AL) by PCR, screening using primers KI-P5 (5'-CATCAGTCAAGCTAGGATCTGCAGTATG-3') and KI-P6 (5'-GCACCATCTATTTCCTGGGTCAAGCT-3'). The BAC clone isolated (250D22 for KIAA0369) was used for direct R-banding fluorescence in situ hybridization (FISH), a technique based on FISH to replicated prometaphase R-banded chromosomes (Takahashi et al. 1990; 1991). For suppression of the repetitive sequences present in the clones, we used human Cot-I DNA (BRL, Rockville, MD) in fivefold excess, as described by Lichter et al. (1990). Labeling, hybridization, rinsing and detection were carried out in a routine manner (Takahashi et al. 1991). The FISH image was captured by Cytovision (Applied Imaging, Sunderland, UK).

\section{Radiation-Hybrid ( $\mathrm{RH})$ mapping}

A panel of RH clones (GeneBridge 4, Research Genetics) representing the whole human genome (Walter et al. 1994) was purchased from Research Genetics. PCR was performed using the primers KI-P5 and KI-P6. The raw data obtained were analyzed by software available through the URL at http://www-genome.wi.mit.edu/cgi-bin/contig/ rhmapper.pl.

\section{Results}

Cloning of Doublecortin and KIAA0369

By examining our private database of human ESTs, we found that one expressed sequence of the clone GEN133H01 (HUM133H01A, accession No. D81162) revealed significant homology with Gallus gallus 18C15 mRNA (accession No. L77700; registered in the database as a differentially expressed gene in developing nervous system of the chicken). This similarity led us to analyze the expression pattern of the human sequence in several tissues, and we confirmed specific expression in fetal brain. To isolate full length cDNA we used the 5'-RACE technique (Frohman et al. 1988). After performing repeated 5'-RACE experiments, we obtained a putative full cDNA sequence of $9.0 \mathrm{~kb}$, which contained an open reading frame (ORF) of 366 amino acids. This gene, which was recently cloned and showed mutations in patients with X-linked lissencephaly and double cortex syndrome, was designated Doublecortin (des Portes et al. 1998; Gleeson et al. 1998).

In a search of protein databases, the deduced amino acid sequence of Doublecortin revealed homology with the 
product of only one archived cDNA, KIAA0369 (accession No. AB002357), originally reported as one of 100 sequences isolated from a human-brain cDNA library (Nagase et al. 1997). The homology between them was $72.5 \%$ identity at the nucleotide level and $72.3 \%$ identity at the amino acid level. When cloned by PCR, KIAA0369 revealed alternative splicing in the $\mathrm{C}$-terminus. The longer variant, containing a 740-amino-acid ORF, we designated KIAA0369-AL (KIAA0369-type A, long version), as opposed to the shorter splice-form, KIAA0369-AS, which contained a 729amino-acid ORF identical to KIAA0369. A search of databases with KIAA0369-AL revealed significant homology with rat cpg16 (accession No. U78857), although the rat sequence lacked an $\mathrm{N}$-terminal region homologous to KIAA0369-A and possessed only the kinase region. We surmised that KIAA0369, like its rat counterpart, might also have an isotype that would lack the $\mathrm{N}$-terminal half. To investigate this possibility we performed 5'-RACE experiments using a primer designed in the $\mathrm{C}$-terminal region common to KIAA0369 and cpg16. We indeed found a short isotype of KIAA0369, 98\% identical to rat cpg16, and designated it KIAA0369-B. Like KIAA0369-A, KIAA0369-B also showed alternative splicing in the $\mathrm{C}$ terminus; the longer variant (KIAA0369-BL) contained an ORF encoding 433 amino acids; the shorter variant (KIAA0369-BS) encoded 422 amino acids. The four splice variants of KIAA0369 are shown in Fig. 1a.

Fig. 1 a Schematic diagram of Doublecortin and variants of KIAA0369. The Doublecortin $(D C)$, serine and proline $(S P)$-rich, and calmodulin-dependent $(\mathrm{CaM})$ kinase-like domains are indicated. b Multiple alignment of Doublecortin, KIAA0369 splicing variants, and rat cpg16. The Doublecortin, SP-rich, and $\mathrm{CaM}$ kinase-like domains are indicated. The nuclear targeting signal-like motif, "KPRK," is underlined
Figure $1 \mathrm{~b}$ shows multiple alignment of Doublecortin, the four KIAA0369 variants, and rat cpg16. Doublecortin and KIAA0369-A each contain a novel, highly conserved domain in the N-terminus, designated the DC domain (Doublecortin domain). A serine- and proline-rich domain (SP-rich domain) follows the DC domain in Doublecortin and is present in all KIAA0369 variants. In KIAA0369, a calmodulin-dependent $(\mathrm{CaM})$ kinase-like domain follows the SP-rich domain. The kinase domain shows relatively greater conservation of CaM kinases II and IV relative to other CaM kinases; sequence alignment of the CaM kinaselike domain of KIAA0369-AL with rat CaM kinase II alpha subunit (CaMK II) is shown in Fig. 2, where conserved blocks I to XVIII of the protein kinase domain are indicated. Doublecortin and KIAA0369-AS also contain a nuclear targeting signal-like sequence (Hicks and Raikhel 1995) in their DC domains.

\section{Developmental and tissue expression of KIAA0369}

The expression of Doublecortin, investigated in 12 different tissues, showed that Doublecortin was expressed specifically in fetal brain (des Portes et al. 1998). To compare the expression of KIAA0369 with that of Doublecortin, we investigated the expression patterns of these two genes in 4 different fetal and 16 different adult tissues by Northern

\section{DC domain}

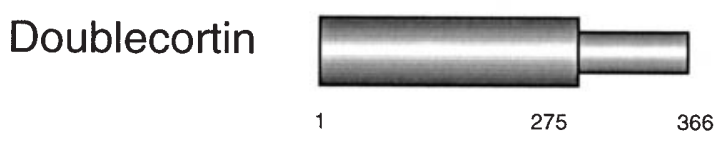

\section{DC domain SP rich CaM kinase like}

KIAA0369-AS
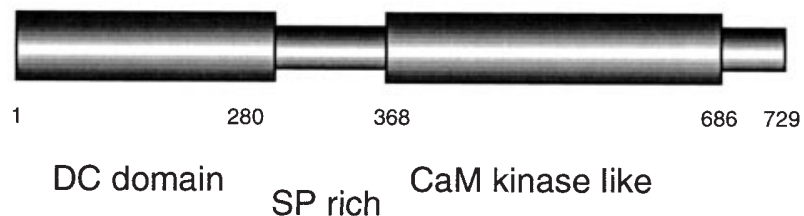

KIAA0369-AL

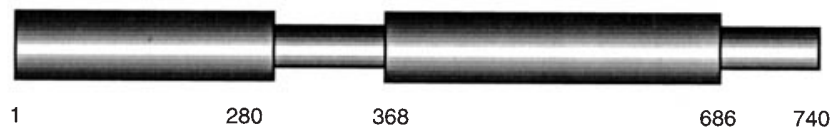

SP rich CaM kinase like

KIAA0369-BS

KIAA0369-BL

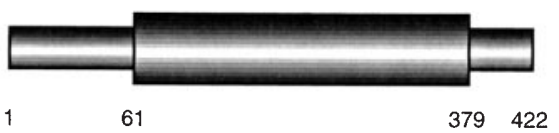

SP rich CaM kinase like

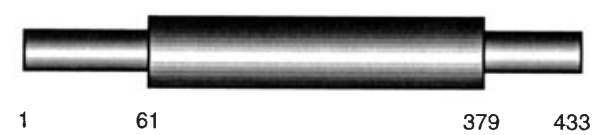


Fig. 1 Continued

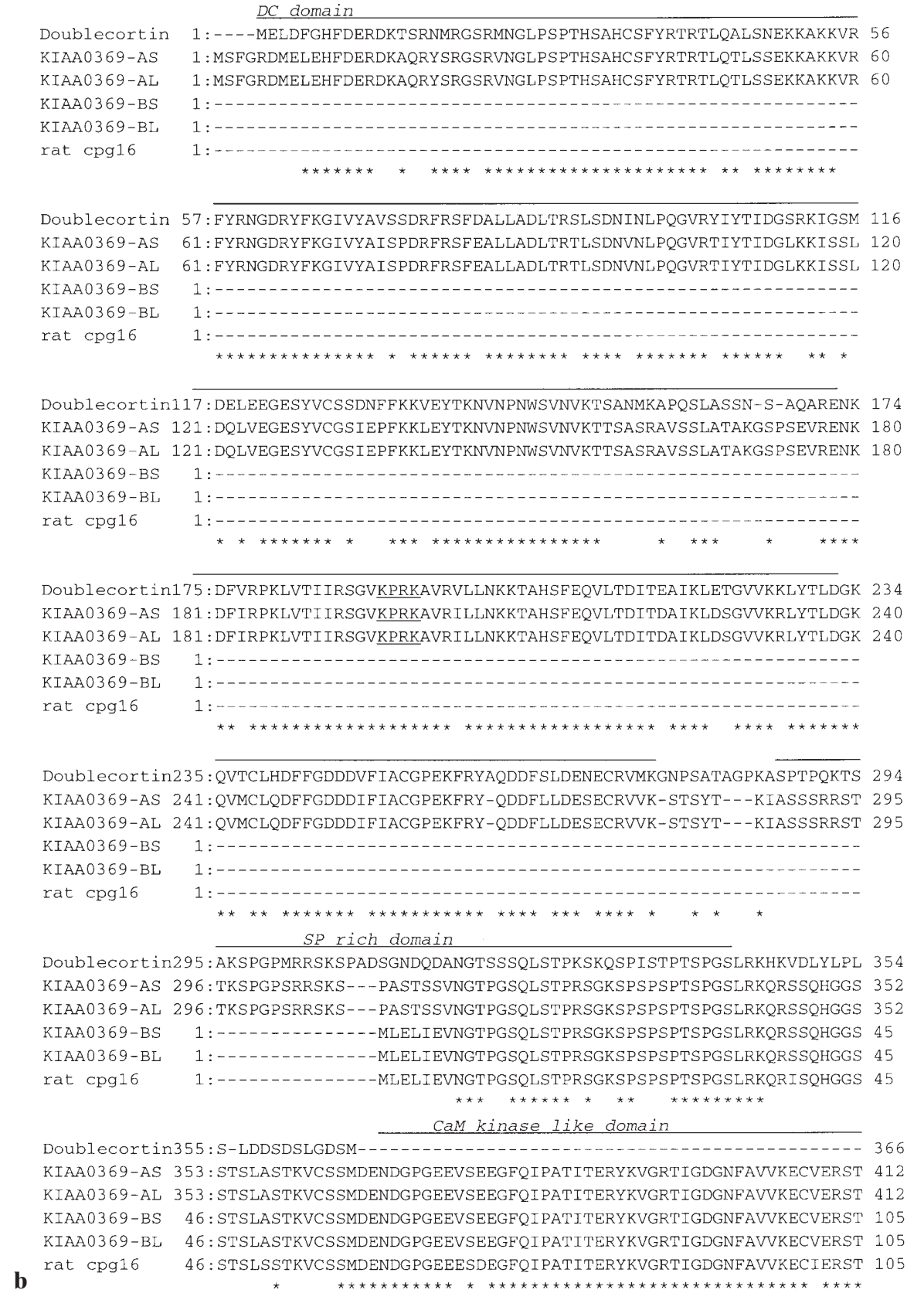

57 : FYRNGDRYFKGIVYAVSSDRFRSFDALLADLTRSLSDNINLPQGVRYIYTIDGSRKIGSM 116 61 : FYRNGDRYFKGIVYAISPDRFRSFEALLADLTRTLSDNVNLPQGVRTIYTIDGLKKISSL 120 :DELEEGESYVCSSDNFFKKVEYTKNVNPNWSVNVKTSANMKAPQSLASSN-S-AOARENK 174 KIAA0369-AS 121:DQLVEGESYVCGSIEPFKKLEYTKNVNPNWSVNVKTTSASRAVSSLATAKGSPSEVRENK 180 KIAA0369-AL 121 :DQLVEGESYVCGSIEPFKKLEYTKNVNPNWSVNVKTTSASRAVSSLATAKGSPSEVRENK 180 KIAA0369-BS KIAA0369-BL rat $\operatorname{cpg} 16$
Doublecortin175: DFVRPKLVTIIRSGVKPRKAVRVLLNKKTAHSFEQVLTDITEAIKLETGVVKKLYTLDGK 234 KIAA0369-AS 181:DFIRPKLVTIIRSGVKPRKAVRILLNKKTAHSFEQVLTDTTDAIKLDSGVVKRLYTLDGK 240 KIAA0369-AL 181:DFIRPKLVTIIRSGVKPRKAVRILLNKKTAHSFEOVLTDITDAIKLDSGVVKRLYTLDGK 240 KIAA0 $369-B S$ KIAA0369-BL rat cpg16

Doublecortin2 35: QVTCLHDFFGDDDVFIACGPEKFRYAQDDFSLDENECRVMKGNPSATAGPKASPTPQKTS 294 KIAA0369-AS 241: OVMCLODFFGDDDIFIACGPEKFRY-ODDFLLDESECRVVK-STSYT---KIASSSRRST 295 KIAA0369-AL 241:QVMCLQDFFGDDDIFIACGPEKFRY-QDDFLLDESECRVVK-STSYT---KIASSSRRST 295 $1:-\cdots-\cdots$ KIAA0369-BL $1:-\cdots-\cdots$

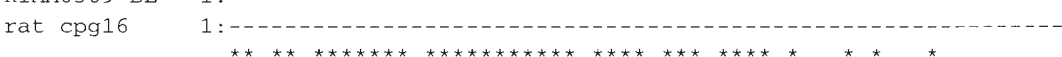
SP rich domain

Doublecortin295: AKSPGPMRRSKSPADSGNDODANGTSSSOLSTPKSKOSPISTPTSPGSLRKHKVDLYLPL 354 KIAA0369-AS 296:TKSPGPSRRSKS---PASTSSVNGTPGSQLSTPRSGKSPSPSPTSPGSLRKQRSSQHGGS 352 269-AL 296:TKSPGPSRRSKS---PASTSSVNGTPGSQLSTPRSGKSPSPSPTSPGSLRKQRSSQHGGS 352 KIAA0369-BL 1:----_-_----MLELIEVNGTPGSQLSTPRSGKSPSPSPTSPGSLRKQRSSQHGGS 45 rat cpg16 1:-...........-MIELIEVNGTPGSOLSTPRSGKSPSPSPTSPGSLRKQRISQHGGS 45 CaM kinase like domain

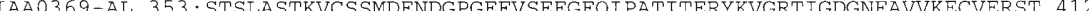
b

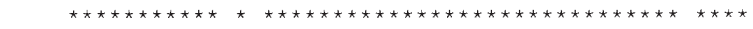

blotting (Fig. 3A). Doublecortin was not detected in any tissues examined other than fetal brain, even after longer exposure (data not shown). For KIAA0369 we constructed two probes, one that contained sequences from the kinase domain and therefore could detect both KIAA0369-A and KIAA0369-B; the other, from the DC domain, could detect only KIAA0369-A. The former probe detected three transcripts, of $8.0 \mathrm{~kb}, 6.0 \mathrm{~kb}$, and $5.0 \mathrm{~kb}$; the latter detected only the 8.0- and 6.0-kb transcripts. The 5.0-kb transcript represented the KIAA0369-B variants, which lack a DC domain, and the $8.0-\mathrm{kb}$ and $6.0-\mathrm{kb}$ bands represented the KIAA0369-A variants, which contain both the DC domain and CaM kinase domain (Fig. 3D). The $8.0-\mathrm{kb}$ and $6.0-\mathrm{kb}$ transcripts detected by the probe of the DC domain were expressed predominantly in fetal brain, but the $5.0-\mathrm{kb}$ transcript was expressed at the same level in adult and fetal brain (Fig. 3A). Thus, transcripts containing the DC domain (i.e., Doublecortin and KIAA0369-A) seemed to be expressed mainly in the developing nervous system; transcripts lacking the DC domain (KIAA0369-B) were also expressed abundantly in mature brain. After longer exposure, a slight degree of KIAA0369 expression was detectable in fetal lung and liver also, and in adult heart, liver, spleen, thymus, prostate, testis, small intestine, and colon (data not shown). Expression of Doublecortin seemed to be restricted to fetal brain, however. Transcripts of KIAA0369 
Fig. 1 Continued

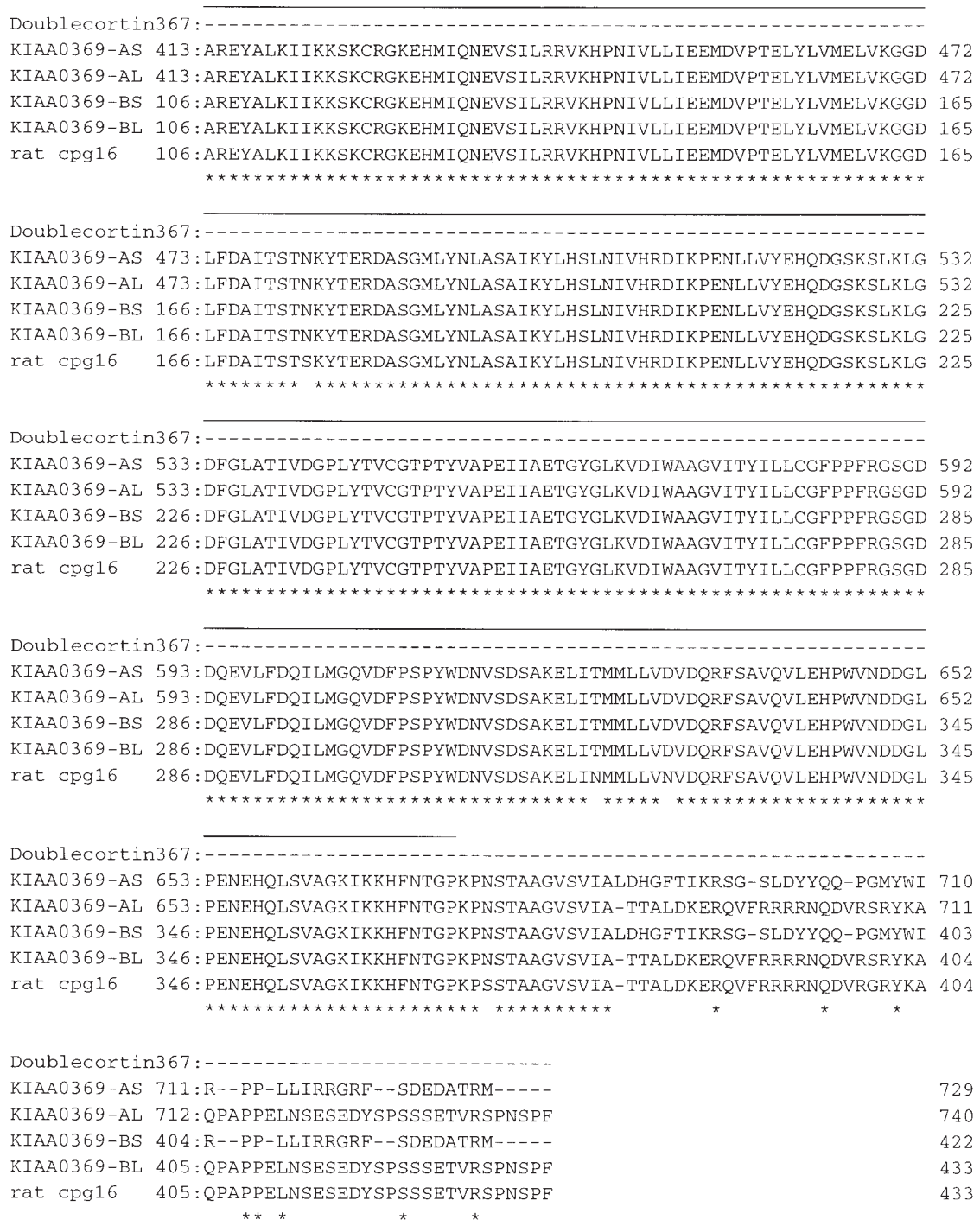

were observed in all 15 regions of the adult brain examined, but expression levels and the ratios of the alternative KIAA0369 transcripts were somewhat different (Fig. 3C). We saw greater intensity of bands representing cerebral cortex, occipital pole, frontal lobe, amygdala, and hippocampus, relative to corpus callosum and thalamus. In terms of ratio, the KIAA0369-B transcript predominated in cerebellum, putamen, and caudate nucleus.

To investigate when expression of these two genes begins in fetal life, we analyzed the expression patterns of the murine homologs in mouse embryos at various stages (Fig. 3B). The murine counterpart of Doublecortin appeared at the size of $10 \mathrm{~kb}$. Expression of Doublecortin was silent before day E (embryonic)-7, but underwent a sudden burst on day E-11 and then decreased gradually on days E15 to E-17. In contrast to the three sizes of the KIAA0369 transcript seen in humans, however, only two were observed in mouse $(9.5 \mathrm{~kb}$ and $6.0 \mathrm{~kb})$. The temporal pattern of KIAA0369 expression in the mouse embryo was identical to that of Doublecortin until after the burst on day E-11; then it showed a gradual increase on day E-15 and retained that level at E-17.
Chromosomal localization of Doublecortin and KIAA0369

To determine the chromosomal locations of KIAA0369, we performed both direct R-banding fluorescence in situ hybridization (FISH) and radiation-hybrid ( $\mathrm{RH})$ mapping. FISH was performed first; a signal corresponding to KIAA0369 was localized to 13q13-q14.1 (Fig. 4).

A marker-based localization by means of $\mathrm{RH}$ mapping (Gene Bridge 4 RH panel; Walter et al. 1994) then assigned KIAA0369 to a locus $100.78 \mathrm{cR}$ from the top of the chromosome-13 linkage group, between markers WI-3374 and D13S756, consistent with the location indicated by FISH.

\section{Discussion}

KIAA0369 existed in at least four splice-forms, all variants expressed predominantly in fetal brain but to some degree in adult brain also. KIAA0369-A, the complete transcript, included the DC domain and also a $\mathrm{Ca}^{2+} /$ calmodulin- 
Fig. 2 Sequence alignment of the CaM kinase- KIAA0369 like domain of KIAA0369-type A, long version (KIAA0369) with rat CaM kinase II alpha sub- CaMK-II unit (CaMK II). Blocks I to XVIII of the protein kinase domain are indicated with underlining. Vertical lines highlight amino-acid identities
KIAA0369

CaMK-II

KIAA0369

CaMK-II

KIAA0369

CaMK-II

KIAA0369

CaMK-II

KIAA0369

CaMK-II

KIAA0369

CaMK-II

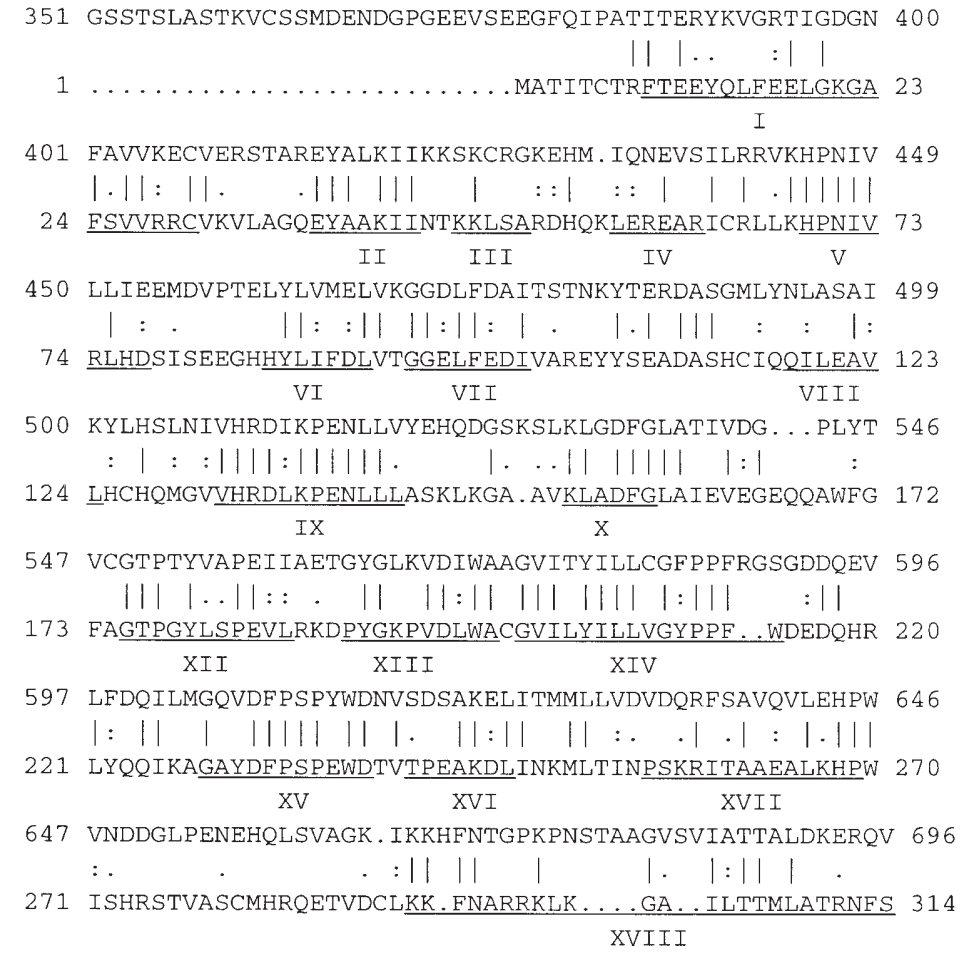

XVIII

pathways and mediate the regulation of many cellular functions, such as muscle contraction, neurotransmitter release, and cell proliferation (Hanson and Schulman 1992; Nairn and Picciotto 1994). Some CaM kinases are abundant in brain; CaM kinase II in particular is of interest in relation to long term potentiation (LTP) in the hippocampus (Soderling 1993; Lisman 1994). KIAA0369-B, lacking the DC domain, is expressed in adult as well as in fetal brain, most abundantly in cerebral cortex, occipital pole, frontal lobe, amygdala, and hippocampus. Our results suggest that KIAA0369 may also participate in functions of the mature nervous system such as LTP.

A feature of CaM kinase II is the existence of several forms that result from alternative splicing in the variable domain that follows the calmodulin-binding domain; these variants have distinct properties such as intracellular localization or tissue-specific expression (Schworer et al. 1993; Brocke et al. 1995). The alternative splicing after the calmodulin binding-like domain in KIAA0369 may, similarly, confer distinct functions in the developing nervous system. Another CaM kinase, myosin light chain kinase (MLCK), regulates cell motility in muscle contractions by phosphorylating myosin light chain (Kamm and Stull 1989). In the developing nervous system a large number of cells or axons must migrate to their fated positions in the embryonic body. It is possible that these two genes (i.e., Doublecortin and KIAA0369) participate in this mechanism.

MLCK possesses a telokin domain in addition to its $\mathrm{CaM}$ kinase domain; alternative splicing produces a protein (telokin) that lacks the entire CaM kinase domain (Gallagher and Herring 1991). Silver et al. (1997) showed that both splice-forms bind to myosin by their telokin do-
All forms of KIAA0369 encode a CaM kinase-like domain. CaM kinases participate in diverse calcium-signaling 


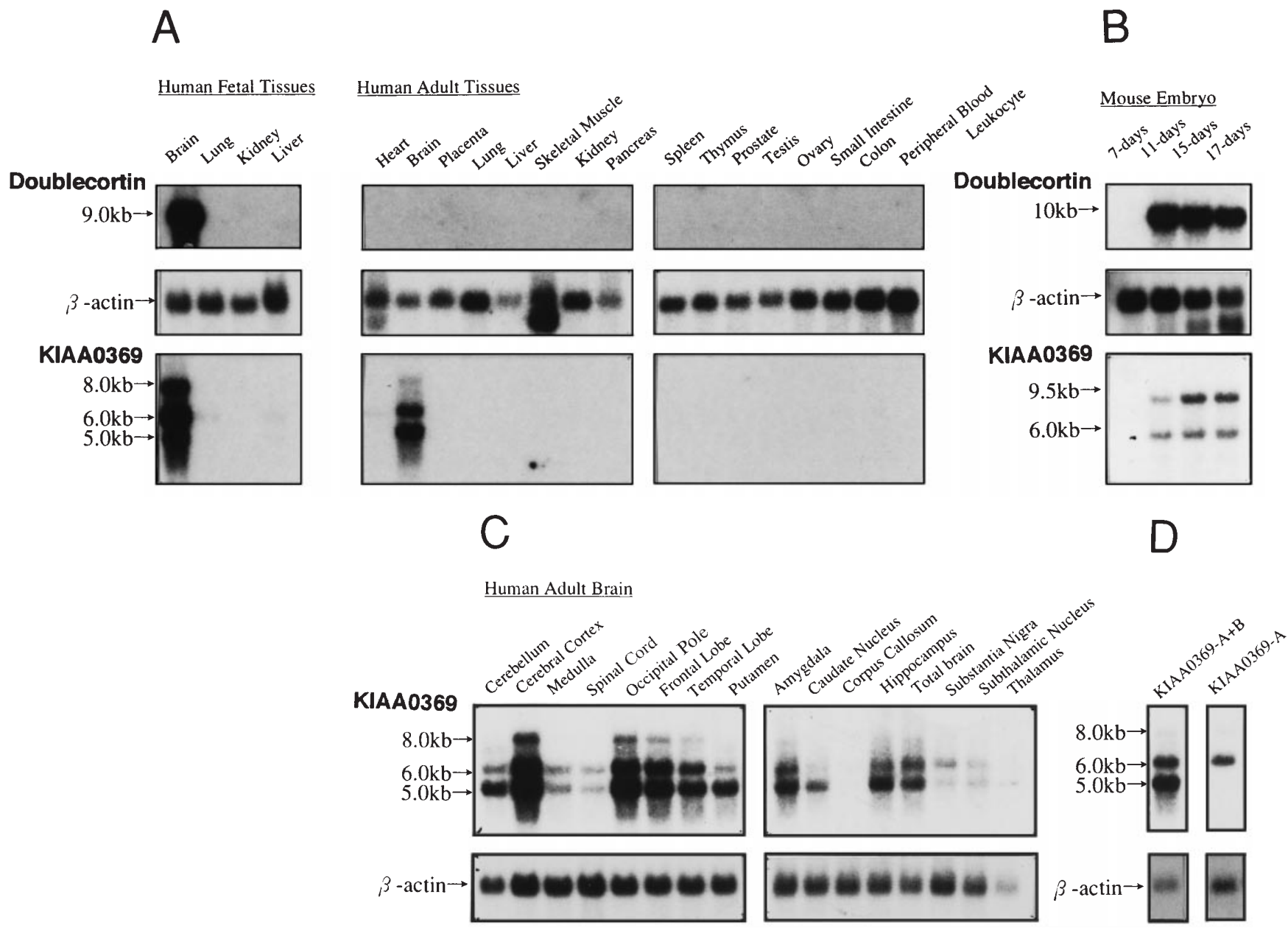

Fig. 3 A Northern-blot analysis of Doublecortin (upper panels) and KIAA0369 (lower panels) in multiple human tissues. B Northern-blot analysis of murine Doublecortin and KIAA0369 homologues in mouse embryo. C Northern-blot analysis of KIAA0369 in human adult brain. D Northern-blot analysis of KIAA0369 splicing variants in human adult brain. Each lane contained approximately $2 \mu \mathrm{g}$ of poly(A) + RNA. The same blots hybridized with a beta-actin probe are shown underneath each panel

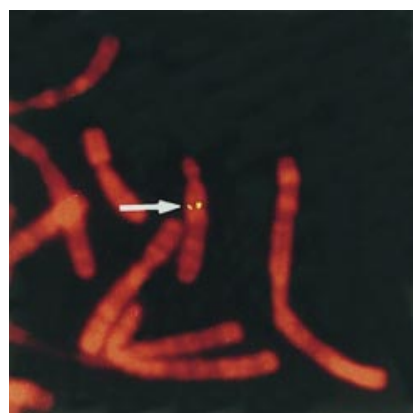

Fig. 4 Partial R-banded metaphase plate after fluorescence in situ hybridization (FISH) with a probe corresponding to KIAA0369. Arrow indicates the signals on 13q13-q14.1

mains, and that telokin on its own competes with MLCK for this binding. This mechanism leads us to hypothesize that Doublecortin, like telokin, competes with KIAA0369 by interacting with its targets of kination, since Doublecortin and KIAA0369 are highly similar in their DC domains and they are both expressed in the developing nervous system. We are very interested in learning what the targets of KIAA0369 are, and whether the DC domain can bind to them.

Both Doublecortin and KIAA0369 contain a nuclear targeting signal-like motif. CaM kinase IV is localized in nuclei (Jensen et al. 1991), and seems to regulate transcription factors by phosphorylating them (Enslen et al. 1995). Whether these genes are localized in nuclei will be another interesting avenue of investigation.

In mouse embryos, Doublecortin expression was not detectable for the first 7 days, but there was a sudden burst of expression on day E-11, followed by a gradual decrease on days E-15 and E-17. Expression of KIAA0369 followed the same pattern until E-11, then increased gradually to E15 and retained that level at E-17. In developing mouse embryo, the primary parts of the brain can be identified soon after the neural groove, neural plate, and head-process stage at 7.5 days, and by 14 days the brain is typically that of a mammal (Rugh 1990). Our results indicate that Doublecortin is more abundantly expressed at earlier stages 
relative to KIAA0369. It is interesting, however, that both of these related genes began to be expressed at the same stage in the mouse embryo and only later showed a different pattern.

Doublecortin is expressed in cortical plate, intermediate zone, and ventricular zone (des Portes et al. 1998). We saw greater intensity of bands of KIAA0369 representing cerebral cortex, occipital pole, frontal lobe, amygdala, and hippocampus, relative to corpus callosum and thalamus. These results mean that these two structurally related genes are expressed in the same or very near region in brain, and suggest a functional relation between them.

It is reasonable to assume that loss of function of any gene involved in the development of neural tissue can lead to abnormalities of the nervous system. Defects in some genes involved in neural development are already known to cause neuropathies in mammals: reelin, a secretory protein, participates in the migration of neurons in the developing nervous system of the mouse, and animals carrying defects in this gene exhibit tremors, dystonia, and ataxia (D'Arcangelo et al. 1995). In humans, mutations of L1, a cell-adhesion molecule involved in neuronal migration and differentiation, cause X-linked hydrocephalus, spastic paraplegia type I, and mental retardation, aphasia, shuffling gait and adducted thumbs (MASA) syndrome (Jouet et al. 1994); and the loss of Sox-3, a DNA-binding protein expressed predominantly in the developing nervous system, has been demonstrated in patients with X-linked mental retardation (Wolff et al. 1997; Mumm et al. 1997). Doublecortin was isolated from the YAC clones near the translocation point and showed mutations in X-linked lissencephaly and double cortex syndrome (des Portes et al. 1998; Gleeson et al. 1998). The missense mutations were found in six pedigrees; Arg to Trp at amino acid (aa) 192, Arg to Leu at aa 59, Thr to Arg at aa 203, Ser to Arg at aa 47, Asp to Asn at aa 62, and Tyr to His at aa 125, respectively. All of these amino acids were also conserved in KIAA0369. These residues will also be important for the expression of functional KIAA0369. We have localized KIAA0369 to $13 q 13-q 14.1$ by FISH and RH. Some syndromes with neuropathy have been mapped to near the KIAA0369 location. Stabile et al. (1984) and Slee et al. (1991) observed deletion of 13q12.2-q13 in Moebius syndrome, in which the patients showed congenital paralysis of the sixth and seventh cranial nerves. Radhakrishna et al. (1997) mapped hidrotic ectodermal dysplasia (Clouston syndrome) to $13 \mathrm{q} 11-\mathrm{q} 12.1$, and some of these patients show mental deficiency.

In view of its expression in the developing nervous system and its chromosomal locations, we believe KIAA0369 is a candidate responsible for these neuropathies.

Acknowledgments We thank all the staff members of the GEN Research Institute for their technical assistance, especially acknowledging Ms. K. Yamada for her excellent technique of sample preparation; $\mathrm{Mr}$. A. Kawai and Ms. Y. Fujii for sequencing; Mr. H. Shinomiya for RH paneling; and Dr. M. Horie for valuable suggestions.

Supported in part by a Grant-in-Aid for Creative Basic Research (Human Genome Project) from the Ministry of Education, Culture and Science of Japan (E.T.).

\section{References}

Brocke L, Srinivasan M, Schulman H (1995) Developmental and regional expression of multifunctional $\mathrm{Ca}^{2+} /$ calmodulin-dependent protein kinase isoforms in rat brain. J Neurosci 15: 6797-6808

D'Arcangelo G, Miao GG, Chen SC, Soares HD, Morgan JI, Curran T (1995) A protein related to extracellular matrix proteins deleted in the mouse mutant reeler. Nature 374: 719-723

des Portes V, Pinard JM, Billuart P, Vinet MC, Koulakoff A, Carrie A, Gelot A, Dupuis E, Motte J, Berwald-Netter Y, Catala M, Kahn A, Beldjord C, Chelly J (1998) A novel CNS gene required for neuronal migration and involved in X-linked subcortical laminar heterotopia and lissencephaly syndrome. Cell 92: 51-61

Enslen H, Tokumitsu H, Soderling TR (1995) Phosphorylation of CREB by CaM-kinase IV activated by CaM-kinase IV kinase. Biochem Biophys Res Commun 207: 1038-1043

Frohman MA, Dush MK, Martin GR (1988) Rapid production of fulllength cDNAs from rare transcripts: Amplification using a single gene-specific oligonucleotide primer. Proc Natl Acad Sci USA 85: 8998-9002

Gallagher PJ, Herring BP (1991) The carboxyl terminus of the smooth muscle myosin light chain kinase is expressed as an independent protein, telokin. J Biol Chem 266: 23945-23952

Gleeson JG, Allen KM, Fox JW, Lamperti ED, Berkovic S, Scheffer I, Cooper EC, Dobyns WB, Minnerath SR, Ross ME, Walsh CA (1998) Doublecortin, a brain-specific gene mutated in human Xlinked lissencephaly and double cortex syndrome, encodes a putative signaling protein. Cell 92: 63-72

Hanson PI, Schulman H (1992) Neuronal $\mathrm{Ca}^{2+} /$ calmodulin-dependent protein kinases. Annu Rev Biochem 61: 559-601

Hicks GR, Raikhel NV (1995) Protein import into the nucleus: An integrated view. Ann Rev Cell Dev Biol 11: 155-188

Jensen KF, Ohmstede CA, Fisher RS, Sahyoun N (1991) Nuclear and axonal localization of $\mathrm{Ca}^{2+}$ /calmodulin-dependent protein kinase type Gr in rat cerebellar cortex. Proc Natl Acad Sci USA 88: 28502853

Johnson JE, Birren SJ, Anderson DJ (1990) Two rat homologues of Drosophila achaetescute specifically expressed in neuronal precursors. Nature 346: 858-861

Jouet M, Rosenthal A, Armstrong G, MacFarlane J, Stevenson R, Paterson J, Metzenberg A, Ionasescu V, Temple K, Kenwrick S (1994) X-linked spastic paraplegia (SPG1), MASA syndrome and Xlinked hydrocephalus result from mutations in the L1 gene. Nat Genet 7: 402-407

Kamm KE, Stull JT (1989) Regulation of smooth muscle contractile elements by second messengers. Annu Rev Physiol 51: 299313

Lee JE, Hollenberg SM, Snider L, Turner DL, Lipnick N, Weintraub H (1995) Conversion of Xenopus ectoderm into neurons by NeuroD, a basic helix-loop-helix protein. Science 268: 836-844

Lichter P, Ledbetter DH, Ward DC (1990) Fluorescence in situ hybridization with Alu and L1 polymerase chain reaction probes for rapid characterization of human chromosomes in hybrid cell lines. Proc Natl Acad Sci USA 87: 6634-6638

Lisman J (1994) The CaM kinase II hypothesis for the storage of synaptic memory. Trends Neurosci 17: 406-412

Mumm S, Zucchi I, Pilia G (1997) SOX3 gene maps near DXS984 in Xq27.1, within candidate regions for several X-linked disorders. Am J Med Genet 72: 376-378

Nagase T, Ishikawa K, Nakajima D, Ohira M, Seki N, Miyajima N, Tanaka A, Kotani H, Nomura N, Ohara O (1997) Prediction of the coding sequences of unidentified human genes. VII. The complete sequences of 100 new cDNA clones from brain which can code for large proteins in vitro. DNA Res 4: 141-150

Nairn AC, Picciotto MR (1994) Calcium/calmodulin-dependent protein kinases. Semin Cancer Biol 5: 295-303

Radhakrishna U, Blouin J-L, Mehenni H, Mehta TY, Sheth FJ, Sheth JJ, Solanki JV, Antonarakis SE (1997) The gene for autosomal dominant hidrotic ectodermal dysplasia (Clouston syndrome) in a large Indian family maps to the 13q11-q12.1 pericentromeric region. Am J Med Genet 71: 80-86

Rugh R (1990) The mouse: Its reproduction and development. Oxford University Press, New York 
Schworer CM, Rothblum LI, Thekkumkara TJ, Singer HA (1993) Identification of novel isoforms of the delta subunit of $\mathrm{Ca}^{2+}$ calmodulin-dependent protein kinase II. Differential expression in rat brain and aorta. J Biol Chem 268: 14443-14449

Silver DL, Vorotnikov AV, Watterson DM, Shirinsky VP, Sellers JR (1997) Sites of interaction between kinase-related protein and smooth muscle myosin. J Biol Chem 272: 25353-25359

Slee JJ, Smart RD, Viljoen DL (1991) Deletion of chromosome 13 in Moebius syndrome. J Med Genet 28: 413-414

Soderling TR (1993) Calcium/calmodulin-dependent protein kinase II: Role in learning and memory. Mol Cell Biochem 128: 93-101

Stabile M, Cavaliere ML, Scarano G, Fels A, Valiani R, Ventruto V (1984) Abnormal BAEP in a family with Moebius syndrome: Evidence for supranuclear lesion. Clin Genet 25: 459-463

Takahashi E, Hori T, O'Connell P, Leppert M, White R (1990) Rbanding and nonisotopic in situ hybridization: Precise localization of the human type II collagen gene (COL2A1). Hum Genet 86: 1416

Takahashi E, Yamauchi M, Tsuji H, Hitomi A, Meuth M, Hori T (1991) Chromosome mapping of the human cytidine-5' -triphosphate synthetase (CTPS) gene to band 1p34.1-p34.3 by fluorescence in situ hybridization. Hum Genet 88: 119-121

Uwanogho D, Rex M, Cartwright EJ, Pearl G, Healy C, Scotting PJ, Sharpe PT (1995) Embryonic expression of the chicken Sox2, Sox3 and Sox11 genes suggests an interactive role in neuronal development. Mech Dev 49: 23-36

Walter M, Spillet D, Thomas P, Weissenbach J, Goodfellow P (1994) A method for constructing radiation hybrid maps of whole genomes. Nat Genet 7: 22-28

Watanabe TK, Fujiwara T, Kawai A, Shimizu F, Takami S, Hirano H, Okuno S, Ozaki K, Takeda S, Shimada Y, Nagata M, Takaichi A, Takahashi E, Nakamura Y, Shin S (1996a) Cloning, expression, and mapping of UBE2I, a novel gene encoding a human homologue of yeast ubiquitin-conjugating enzymes which are critical for regulating the cell cycle. Cytogenet Cell Genet 72: 86-89

Watanabe TK, Fujiwara T, Shimizu F, Okuno S, Suzuki M, Takahashi E, Nakamura Y, Hirai Y (1996b) Cloning, expression, and mapping of TCTEL1, a putative human homologue of murine Tcte1, to 6q. Cytogenet Cell Genet 73: 153-156

Wolff DJ, Gustashaw KM, Zurcher V, Ko L, White W, Weiss L, Van Dyke DL, Schwartz S, Willard HF (1997) Deletions in Xq26.3-q27.3 including FMR1 result in a severe phenotype in a male and variable phenotypes in females depending upon the $\mathrm{X}$ inactivation pattern. Hum Genet 100: 256-261

Wright E, Hargrave MR, Christiansen J, Cooper L, Kun J, Evans T, Gangadharan U, Greenfield A, Koopman P (1995) The Sry-related gene Sox 9 is expressed during chondrogenesis in mouse embryos. Nat Genet 9: 15-20 